\title{
Preschool Teachers' Perspectives on the Importance of STEM Education in Greek Preschool Education
}

\author{
Alexandros Baltsavias ${ }^{1} \quad$ Argyris Kyridis $^{2}$ \\ 1.School of Early Childhood Education, Aristotle University of Thessaloniki, Greece. \\ E-mail: alexandmc@nured.auth.gr \\ 2.Professor of Sociology, Sociology of Education and Research Methods, School of Early Childhood Education, \\ Aristotle University of Thessaloniki, Greece \\ E-mail of the corresponding author: akiridis@nured.auth.gr
}

\begin{abstract}
Given the rapid development of technology and therefore of society in recent years, the need for education systems worldwide to modernize the methods and means used is a matter of necessity. In the present study, this modernization translates into the application of STEM education and deepens into the research of preschool teachers' perspectives on the importance of STEM in Greek preschool education. Investigating teachers' perceptions is a complex process, through which we are examining the pedagogical methods they use in their classrooms, their knowledge of STEM approaches and the understanding of the usefulness of STEM education. It is well known that teachers' perceptions can influence instructional choices. Therefore, it is necessary to investigate their perceptions of STEM education, in order to take action timely and explore the prospects for the school of future. In this dissertation, we are thoroughly investigating preschool teachers' perspectives on their role in the classroom, but also on the importance of integrating the instruction of STEM disciplines in early years. The research findings show high percentage agreement in relation to the perspectives on the usefulness of STEM, but when it comes to analyzing responses regarding the implementations of STEM, teachers are hesitating to respond with absolute certainty. The presentation of an ideal situation however, is far from reality, as STEM education also requires a proper preparation and training for the kindergarten teachers. However, their positive perspectives on STEM can be the first step in integrating the element of innovation into pre-school education.
\end{abstract}

Keywords: STEM, innovation, teaching methods, education curricula, teachers, perspectives.

DOI: $10.7176 / \mathrm{JEP} / 11-14-01$

Publication date:May $31^{\text {st }} 2020$

\section{Introduction}

In recent years, there has been a prompt increase in the growth rate of technology, both in Greek and global society. The way society responds to change reveals the avidity and readiness of people to adapt to new situations (Heylighen, 2007; Katsikas \& Gritzalis, 2017). One issue that is of concern to education, is that schools must keep pace with social development and create people capable of coping with ever-changing circumstances. Hence, a new need for educational systems is being cultivated, so that society consists of people who are capable and ready to meet the challenges of the modern world. Just as in the industrial revolution there was the need for children to learn how to read, nowadays the technological revolution that the society is experiencing, invites students to become acquainted with STEM (McClure et al., 2017). Developing countries that are searching out for an economic boost invest in education and training to create a strong workforce. (Office of the Chief Scientist, 2014; Riegle-Crumb, King, Grodsky, \& Muller, 2012 as cited in McDonald, 2016). In STEM education, knowledge is at first constructed through teaching math and science. The complex process of knowledge construction includes the understanding of mathematical and scientific concepts, which subsequently leads to creating a clearer perception of the wider and more abstract fields of technology and engineering (Hernandez et al., 2014 in McDonald, 2016). Based on the literature review, it is well known that early years are critical for the child's development, as children come into contact with stimuli that contribute to the formation of a conscious perception of how the world works. In particular, at the ages of 1-4, the human brain is very receptive to learning mathematics and logic. (Chesloff, 2013, in Aldemir, Kermani, 2017). However, a simple research on the importance of STEM integration in modern preschool educational programs is insufficient. All the factors that affect children's developmental period from the ages of 4-6, should be alerted for the need of an educational update.

\section{Literacy Review}

\subsection{Prior Studies}

With regards to the foreign literature, there are numerous studies that emphasize the importance and usefulness of STEM education. For instance, Madden, Beyers \& O'Brien's study (2016). reviews young teachers' or pre-service teachers' perceptions of the importance of STEM in elementary grades in America. They particularly sought to understand how novice teachers perceive STEM education in primary school. Also, they investigated the reasons why young teachers consider STEM important and then analyzed them. They elaborated the arguments noted on 
the questionnaire's responses and categorized them by the quantity, the nature and the type of reasons given by the respondents on why STEM is important. The sample consisted of young teachers and recently graduates of a US college, which is characterized by high achieving students. The findings of Madden, Beyers and O'Brien's (2016) research holds great promise for STEM Education, but also sets some necessary conditions for its successful implementation. A fairly positive assumption is that teachers agree on the importance of STEM education. Although, this perception is not backed up with valid data or enough appropriate argumentation. It appears that teachers are not sufficiently trained to teach STEM and have not adopted a thorough view of STEM education from their education before serving in school. Over those conclusions, Madden, Beyers and O'Brien get a glimpse of how the school of future will look like. In order to complete the vision of STEM education they suggest some adjustments made in the educational systems, that will help create trained and capable teachers.

Another study that highlighted teachers' perspectives on the importance of STEM is that of Brown R. et al., conducted in 2011 in the United States. This research initially aimed at exploring teachers' perceptions of STEM related fields and their knowledge, of how important it is to implement it in modern curricula and to which students it may be beneficial. Moreover, they attempted to examine with questionnaires teachers' perspectives on how the application of STEM education will result a change in their teaching methods. Lastly, they investigated the frequency rate of teachers' tendency to co-operate with each other in order to teach STEM and the sources from which teachers were informed of STEM practices. After completing the data analysis, the research concluded to three particular findings. First, "STEM education is not fully understood", even by those that teach one of the four subject areas of STEM. Second, there is no common "clear vision" for STEM education, even those who claim that STEM is important have a perplexed perception of it. Third and last conclusion is the fact that there is little evidence that proves STEM education is being applied in school. The lack of cooperation between teachers and people who have substantial knowledge in STEM, is sufficient to cause this phenomenon.

After extensive research, it turned out that there are no previous studies reviewing preschool teachers' perspectives on the importance of STEM education in Greek preschool education. In general, the Greek research community appears to focus on the integration of innovation through the use of ICTs (Information and Communication Technologies) in the classroom. Nonetheless, there are several studies that examine STEM education through different pedagogical perspectives, but none of them highlights teachers' perspectives.

\subsection{Theories that support STEM Education}

In order to comprehend how STEM education is structured and the pedagogical methods correlated with it, it is necessary to gain an insight on the fundamentals of the four disciplines. Like any other educational approach and practice, STEM is based on theories related to the cognitive, physical and psychological development of the child. In particular, STEM relies heavily on Lev Vygotsky's (1978) socio-cultural theory. According to this theory, learning is a social process and human intellect arises from society or culture and the interactions made into those two. Generally, Vygotsky believed that a person's social interactions are directly related to his cognitive development and that children's experiences in the social environment shape their perception of the world. Also, children's cultural development begins first in the social context, through contact with other people and then in the child's inner world (Vygotsky, 1978 as cited in Aguilar, 2016). In STEM education, great emphasis is placed on the social context, as one of its main goals is to provide children knowledge that will help support their adaptation to the continuous social changes. The practices and means used for the instruction of STEM fields, are adapted to the current social conditions and by that, children get to know different types of communication, new devices and other features that modern society uses. In addition, Vygotsky (1978, as cited in Aguilar 2016) pointed out that children learn easily through its daily activities and through play time. It is therefore necessary to create a healthy environment for the students, that reflects our social reality, so that children can adapt to this reality smoothly in the future.

Apart from Vygotsky's socio-cultural theory, STEM education is based on the ecological systems theory of Urie Bronfenbrenner (1977), which is indirectly linked to the need for innovation. According to Bronfenbrenner (1977), in order to clearly understand the developmental process that children go through the early years, it is compulsory to analyze their interactions within wider "systems", in which they belong and may affect them. (Bronfenbrenner, 1977 as cited in Mc.Clure et al., 2017). In the educational context, those systems affect greatly child's development. In his theory, these systems are analyzed in detail and are named: the microsystem, the mesosystem, the exosystem and the macrosystem. The theory of ecological systems is characterized by "homocentrism", which shows that each system successively affects every smaller. However, this does not mean that the child remains passive in this interaction, but actively participates in the process, by influencing the way

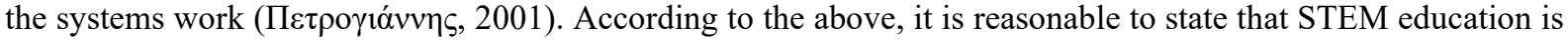
mostly based on social patterns, circumstances and changes that are taking place in the time of speaking, so that the new generation can adapt dynamically to the modern society. 


\section{Method}

The purpose of this study is to investigate kindergarten teachers' perspectives on the importance of STEM in Greek pre-school education. At the same time, this study explores different aspects of STEM's implementation in preschool education and serves several purposes such as.

1. Investigating how familiar are preschool teachers with STEM fields.

2. Examining how often are STEM practices used in a Greek preschool classroom

\subsection{Research Tool}

The platform used to create the questionnaire was Google Forms. The questionnaires were distributed to the teachers via e-mail and their responses were recorded through the platform. The survey lasted 1 month approximately and the responses were regularly checked during this month. The questionnaire was split to 6 sections: the demographic variables, teachers' perspectives on their role and their perspectives on STEM (a section for each subject area).

Apart from the demographic questions, teachers responded on a five-point Likert agreement scale in every section of the questionnaire. The questionnaire's structure was determined after a short literacy review on the subject. In order to create the questions, data was extracted from the education curriculums of Cyprus and Queensland state of Australia. Thus, it would be easier to highlight the importance of STEM and the instruction of its subject areas through different perspectives. Drawing this information from those two curriculums and integrating it in the questionnaire, creates the opportunity for the research to display the differences between education systems. It also allows the teachers to express their views on the importance of STEM, but also to report on the practices used in Greek preschool education.

\subsection{Sample}

The research sample consists of 210 current kindergarten teachers and substitute kindergarten teachers that teach in kindergartens around Greece. There were no restrictions on the sample selection, as the questionnaires were distributed to random teachers. Sample numbers portray a feminized profession, as only 2 out of 210 teachers were men. As for the ages of the respondents, they range between the categories "under 30" and "60 and over".

Table 1.1: Age

\begin{tabular}{lll} 
& $\mathrm{N}$ & $\%$ \\
\hline$<30$ years old & 43 & 20,5 \\
30-40 years old & 90 & 42,9 \\
$41-50$ years old & 56 & 26,7 \\
$51-60$ years old & 20 & 9,5 \\
$>60$ years old & 1 & 0,5 \\
\hline & 210 & 100,0 \\
\hline
\end{tabular}

According to Table 1.1, the largest percentage of teachers questioned were kindergarten teachers of 30-40 years old, followed by the category of 41-50 years old teachers and then kindergarten teachers under 30 . There were also a few teachers over the age of 50.

\begin{tabular}{llc}
\multicolumn{3}{c}{ Table 1.2: Years of Service } \\
& $\mathrm{N}$ & $\%$ \\
\hline$<5$ years & 62 & 29,5 \\
6-10 years & 27 & 12,9 \\
11-20 years & 98 & 46,7 \\
$>21$ years & 23 & 11,0 \\
\hline & 210 & 100,0 \\
\hline
\end{tabular}

Kindergarten teachers with less than 5 years of experience and 11-20 years of experience are the largest percentage of kindergarten teachers surveyed. Less teachers have serviced for 6-10 years, while even fewer are kindergarten teachers with over 21 years of service. In addition, teachers were not required to know STEM or be familiar with its practices. The anonymity of the respondents was ensured, as teachers were informed from the beginning, that their responses will be used exclusively for research purposes.

\subsection{Reliability}

An essential part of the research is testing reliability, that is to say how consistently a method measures data. In this occasion it is the reliability of the research tool that needs to be assured. The data collected with the research tool should be precise, so that the findings of the research can portray an accurate situation. In this study, the questionnaire's reliability is tested with the Cronbach's Alpha coefficient. The acceptable values for a reliable tool range between $0.7-1$. Hence, the results displayed in the table below, reveal that the research tool is notably reliable. 


\begin{tabular}{ll}
\multicolumn{2}{c}{ Table 2.1 Sections' Reliability } \\
& Cronbach's Alpha \\
\hline Section A &, 733 \\
Section B &, 887 \\
Section C &, 944 \\
Section D &, 901 \\
Section E &, 922 \\
\hline
\end{tabular}

\subsection{Research Questions}

In the present study, a questionnaire was used to investigate teachers' perspectives on the importance of STEM education in kindergarten. The questionnaire consists of multiple structured questions, that served the purposes of the research. The analysis of the aims and objectives thoroughly stated above, raises several questions that need to be answered in order analyze STEM's importance. Those questions are:

- What practices do preschool teachers claim that they use concerning the instruction of STEM fields?

- How useful is it for preschool teachers to modernize the means used to teach their students?

- How useful is it from a teacher's perspective to provide children STEM education in order to prepare them for the challenges of the modernized world?

- Are teachers properly trained to apply STEM into their classrooms?

\section{Data Analysis}

Table 3.1: Teacher's role

\begin{tabular}{|l|l|l|}
\hline & Mean & $\begin{array}{l}\text { Std. } \\
\text { Deviation }\end{array}$ \\
\hline A.1 I consider myself familiar with STEM related fields. & 3,71 &, 921 \\
\hline $\begin{array}{l}\text { A.2 My classroom's environment includes the instruction of subject areas suggested } \\
\text { by the preschool curriculum. }\end{array}$ & 4,15 &, 597 \\
\hline $\begin{array}{l}\text { A.3 My classroom's environment gives children the opportunity to learn through play } \\
\text { time. }\end{array}$ & 4,38 &, 593 \\
\hline $\begin{array}{l}\text { A.4 My classroom's environment gives children the opportunity to learn through } \\
\text { communication and exploration. }\end{array}$ & 4,23 &, 601 \\
\hline $\begin{array}{l}\text { A.5 I consider useful for children to get acquainted with complex STEM (Science, } \\
\text { Technology, Engineering, Mathematics) concepts. }\end{array}$ & 4,23 &, 660 \\
\hline $\begin{array}{l}\text { A.6 I consider STEM education useful and effective for children with learning } \\
\text { disabilities. }\end{array}$ & 3,83 &, 768 \\
\hline $\begin{array}{l}\text { A.7 I consider that the instruction of STEM subject areas will attract the attention of } \\
\text { boys and girls equally. }\end{array}$ & 4,13 &, 756 \\
\hline $\begin{array}{l}\text { A.8 I feel comfortable with creating a student-centered environment in my classroom, } \\
\text { in which the teacher will not be completely in charge. }\end{array}$ & 3,99 &, 886 \\
\hline $\begin{array}{l}\text { A.9 I am willingly looking to expand my knowledge of STEM's educational } \\
\text { approaches. }\end{array}$ & 3,98 &, 902 \\
\hline
\end{tabular}

The statistics presented in Table 3.1 show that teachers are familiar with STEM fields, but not on a satisfactory level. However, they recognize how important their role is in the classroom and the responsibilities associated with it. Teachers respond with a high level of agreement to questions related to the environment they create in their classrooms and how it promotes the child's development. The level of agreement descents in their responses about the instruction of STEM to children with learning disabilities. Moreover, most teachers think that STEM will attract girls as much as boys, but they agree less on building a student-centered classroom environment. With regard to the information about STEM fields provided to the teachers, they claim that they seek willingly courses to develop a better understanding either on STEM in general or on some of its subject areas separately. 


\begin{tabular}{|l|l|l|}
\hline & Mean & $\begin{array}{l}\text { Std. } \\
\text { Deviation }\end{array}$ \\
\hline B.1 I consider the inclusion of technology in modern education curricula necessary. & 4,24 &, 692 \\
\hline $\begin{array}{l}\text { B.2 I consider important for the teachers to upgrade the instructional process with the use } \\
\text { of modern means. }\end{array}$ & 4,50 &, 589 \\
\hline B.3 In my teaching methods I consider important the use of technology as a tool for the teacher. & 4,27 &, 730 \\
\hline B.4 In my teaching methods I consider important the use of technology as a tool for the student. & 4,01 &, 770 \\
\hline B.5 I consider the use of technology in school important for the child's development. & 4,26 &, 657 \\
\hline B.6 The use of technology will increase my students' cognitive skills. & 4,22 &, 597 \\
\hline $\begin{array}{l}\text { B.7 If I want to search for information on a topic and present it to my students, I will firstly } \\
\text { use the computer in my classroom. }\end{array}$ & 4,13 &, 887 \\
\hline $\begin{array}{l}\text { In my classroom the use of technology means the use of: } \\
\text { - B.8 Digital Books }\end{array}$ & 3,51 & 1,138 \\
\hline B.9 Digital Camera & 3,72 & 1,129 \\
\hline B.10 Educational Software & 3,93 & 1,115 \\
\hline B.11 I consider useful for preschoolers to get in contact with technology from the early years. & 3,94 &, 816 \\
\hline B.12 I consider useful for children to pretend that they use technology in their play time. & 3,31 &, 873 \\
\hline B.13 I consider useful for preschoolers to use real technology during their play time. & 3,28 & 1,008 \\
\hline B.14 I consider useful for children to use technology in order to search information. & 3,98 &, 773 \\
\hline
\end{tabular}

In the Technology section the results showed that teachers mostly agree with the use of technology and the modernization of the means used in education. Increased level of agreement is noted also on the use of technology in preschool education, since teachers believe it affects positively the child's development. Teachers may respond positively to the questions about their perspectives on technology, although a decreased level of agreement is observed in questions with regard to their actual use of technology in their classroom. Also, respondents consider more useful for the teacher to use technology in order to search information, rather than the student to do so. Lastly, the statistics show a large decrease in the level of agreement for teachers' perspectives on the use of technology in children's play time, even if children pretend to play with technology.

Table 3.3: Mathematics

\begin{tabular}{|c|c|c|}
\hline & Mean & $\begin{array}{l}\text { Std. } \\
\text { Deviation }\end{array}$ \\
\hline $\begin{array}{l}\text { C.1 I include the subject area of mathematics in the activities that I engage my students } \\
\text { into. }\end{array}$ & 4,10 & ,685 \\
\hline $\begin{array}{l}\text { C.2 I consider important to engage preschool students in numeracy and operations } \\
\text { activities, so that children learn to: } \\
\text { - represent and recognize numbers. }\end{array}$ & 4,19 & ,818 \\
\hline - $\quad$ C.3 count up to 10. & 4,27 & ,786 \\
\hline - $\quad$ C.4 analyze and synthesize numbers up to 10 . & 4,12 & 842 \\
\hline $\begin{array}{l}\text { C.5 I consider important to engage preschool students in measurement activities so that } \\
\text { children learn to: } \\
\text { - compare object sizes using units of measurement. }\end{array}$ & 4,23 &, 823 \\
\hline - C.6 recognize currencies and use them in their everyday life & 3,96 & 849 \\
\hline - $\quad$ C.7 understand the concept of time and how it is measured & 4,17 & ,816 \\
\hline $\begin{array}{l}\text { C. } 8 \text { I consider important to engage preschool students in geometry activities, so that } \\
\text { children learn to: } \\
\text { - recognize and name shapes }\end{array}$ & 4.38 &, 755 \\
\hline - C.9 distinguish their properties & 4,10 & ,885 \\
\hline - C.10 to analyze and synthesize shapes & 4,17 & 845 \\
\hline - C.11 create shapes & 4,32 & ,783 \\
\hline $\begin{array}{l}\text { C.12 I consider important to engage preschool students in algebra activities, so that } \\
\text { children learn to: } \\
\text { - compare objects based on their properties }\end{array}$ & 4,06 & ,926 \\
\hline - $\quad$ C.13 recognize and describe patterns & 4,07 & 880 \\
\hline $\begin{array}{l}\text { C.14 I consider important for preschool students to use mathematical concepts and use } \\
\text { them in their everyday life. }\end{array}$ & 4,16 & ,757 \\
\hline C.15 I consider important to encourage children to use the language of ma & 4,10 & ,731 \\
\hline
\end{tabular}


The statistics in the table 3.3, indicate high levels of agreement in reference to the field of mathematics that is included in STEM education. Teachers assert that they use math in the activities that take place in their classroom. In this section, questions are split into the usefulness of each math unit, as presented by the education curriculums reviewed. The statistics reveal that teachers consider geometry and numeracy the most useful math units for early years and less useful the units of measurement and algebra. Nonetheless, they have a positive view overall and they affirm that we should encourage children to use "mathematical language" in order to make connections with mathematical concepts in their everyday reality.

Table 3.4: Science

\begin{tabular}{|l|l|l|}
\hline & Mean & $\begin{array}{l}\text { Std. } \\
\text { Deviation }\end{array}$ \\
\hline D.1 I include the subject area of Science in the activities that I engage my students into. & 3,89 &, 784 \\
\hline $\begin{array}{l}\text { D.2 Children develop scientific literacy in my classroom through play-time and } \\
\text { activities led in various learning centers. }\end{array}$ & 4,11 &, 651 \\
\hline $\begin{array}{l}\text { D.3 I consider important to engage preschool students in science activities, so that } \\
\text { children: } \\
\bullet \quad \text { Learn to observe events through a scientific view }\end{array}$ & 3,92 &, 901 \\
\hline$\quad$ D.4 develop scientific literacy $\quad$ D.5 create positive attitudes towards STEM & 3,95 &, 927 \\
\hline$\quad$ D.6 understand concepts &, 927 &, 772 \\
\hline $\begin{array}{l}\text { D.7 I consider important for children to be able to: } \\
\text { - D.9 } \text { takpress part in experiments and share their findings }\end{array}$ & 4,22 &, 764 \\
\hline $\begin{array}{l}\text { D.10 I consider important for the kids to conduct experiments and explore, using } \\
\text { objects. }\end{array}$ & 4,56 &, 664 \\
\hline $\begin{array}{l}\text { D.11 I consider important for children to take active part in experiments and discuss } \\
\text { about their failures. }\end{array}$ & 4,53 &, 690 \\
\hline
\end{tabular}

The data in table 3.4 shows that engaging in science activities is not promoted likewise the field of mathematics in teachers' classrooms. While the development of scientific literacy is considered useful in the everyday routines and activities, teachers state that it is less useful for the children to observe everyday events through a scientific point of view. Also, according to teachers' perspectives, the instruction of science in preschool is useful, as it helps children understand complex concepts and build up attitudes towards STEM and life in general. Similarly, high levels of agreement highlight how appropriate and important it is for the children to express hypothesis and curiosity and conduct experiments and take active part in them to understand the world around them.

Table 3.5: Engineering

\begin{tabular}{|l|l|l|}
\hline & Mean & $\begin{array}{l}\text { Std. } \\
\text { Deviation }\end{array}$ \\
\hline $\begin{array}{l}\text { E.1 I consider the inclusion of engineering important in the modern educational } \\
\text { curricula. }\end{array}$ & 3,74 &, 777 \\
\hline $\begin{array}{l}\text { E.2 I consider the useful to engage my students in engineering activities that combine } \\
\text { all STEM fields }\end{array}$ & 3,80 &, 836 \\
\hline $\begin{array}{l}\text { E.3 I consider important to engage my students in activities that require engineering } \\
\text { thinking, so that they: } \\
\text { - Interconnect experiences and ideas. }\end{array}$ & 4,12 &, 855 \\
\hline$\quad$ E.4 Investigate and solve problems & 4,15 &, 828 \\
\hline$\quad$ E.5 Create strategies to test hypothesis and solve problems & 4,07 &, 858 \\
\hline$\quad$ E.6 Self-reflect on their actions & 4,18 &, 828 \\
\hline
\end{tabular}

In Table (3.5) the statistics reveal that teachers believe that Engineering is the least useful STEM field for preschoolers. Similarly decreased numbers appear concerning their perception of integrating Engineering in modern curricula. However, with respect to the skills acquired through the instruction of Engineering in early years, most teachers find these skills useful for their cognitive development. 
Table 3.6: Total Statistics

\begin{tabular}{lll} 
& Mean & Std. Deviation \\
\hline Mean A & 4,0703 &, 42562 \\
Mean B & 3,9503 &, 54797 \\
Mean C & 4,1590 &, 60901 \\
Mean D & 4,2822 &, 51815 \\
Mean E & 4,0111 &, 70438 \\
\hline Total Mean & 4,0946 &, 45108 \\
\hline
\end{tabular}

Summarizing the analysis of the data collected through the questionnaire, it is reasonable to state that teachers tend to respond with confidence and agree more on perspectives regarding the subject areas they are familiar with, such as Science and Math. High levels of agreement also appeared on the questions concerning the teacher's role in the classroom and the responsibilities linked to this role. Most of the teachers questioned also have a positive perspective on the instruction of Technology and Engineering but they do not consider it as useful as the subject area of Math and Science. This lack of confidence in their responses may be due to their little experience in integrating the element of innovation in education.

\subsection{Distribution Test}

To test the distribution of a variable and examine whether it matches the characteristics of a normal distribution we used the Kolmogorov-Smirnov test. The results of this test showed that the sample's responses present similar characteristics with those of a normal distribution.

\section{Conclusions}

\subsection{Teacher's Role}

The final step is to draw inferences from the results of the research and discuss the observations made. Through their responses, teachers appear to have positive views on the importance of their role and the responsibilities associated with it in the classroom. In spite of the fact that teachers are not very familiar with STEM fields, they create a healthy environment in their classroom that promotes children's development. As suggested in the preschool education curriculum of Cyprus, teachers must cultivate a learning culture so that children develop a positive attitude towards learning, which subsequently will help them overcome obstacles in their future

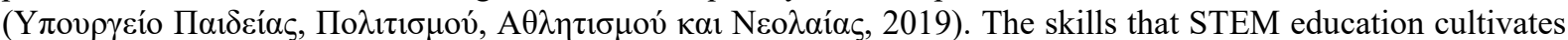
though, are mostly related with their ability to recognize, apply and incorporate concepts from the fields of Science, Technology, Engineering and Mathematics, in order to achieve goals and solve complex problems using the element of innovation (Mc.Clure et. Al.,2017). Teachers appear to be quite skeptical when it comes to conveying this knowledge through STEM to students with learning disabilities or girls. However, research has highlighted the results on students receiving this type of education, as they gain greater opportunities in terms of professional careers (Basham \& Marino, 2010 as cited in Hwang, Taylor, 2016). Also, gender differences in cognitive abilities do emerge in early years, but there is insufficient research biological evidence that rationalize boys' increased interest in STEM (Wang \& Degol, 2017). Boys are more receptive to mathematic knowledge, but it is more likely that it is the environment and not biological factors that affect girls' interest in STEM. Findings show that the sociocultural impact and in particular gender-based stereotypes are the main reasons for female's underrepresentation in STEM fields (Hwang, Taylor, 2016). The teacher is also a role model for his students, thus if he is a STEM enthusiast then this attitude is either consciously or unconsciously adopted by the children (Mc.Clure et al., 2017).

\subsection{Technology}

In the technology section, teachers appear to have a positive perspective on the usefulness of integrating technology in preschool education. Although, they respond with less confidence to the questions about their actual use of technology in the classroom. In recent years technology has been in the spotlight and it is both theoretically and practically the tool that organizes modern society and regulates its functionality. Consequently, it is considered rather useful for preschool education curricula to include the subject area of technology in their content, so that students can get in contact with it from the early years, build their "digital citizenship identity" and learn how to use it (Lindeman, Jabot \& Berkley, 2013). A further novel finding is that teachers find it more useful for the teacher rather than the student to use technology as a tool during the instructional process that takes place in the classroom. In modern society, technology gives children the idea of the division of the real and the artificial world. This is rather significant for the children to realize from the early years, with the intention of understanding the use of technology as a tool to simplify our everyday reality and to make us effective in our activities (Lindeman, Jabot \& Berkley, 2013). The last few years few years the integration of technology in preschool education has been proved critical for the child's development, as its positive effects help students overcome learning barriers, support their skills and create a healthy environment adjusted to every child's needs (Plowman, Stephen, 2005 as cited in Drigas, 
Kokkalia, 2014). Also, the results demonstrated that teachers agree with the use of technology in an organized classroom environment. This finding corroborates with what Zaranis, Kalogiannakis \& Papadakis (2013) cited in Drigas \& Kokkalia (2014) about the need of children to use their skills and apply their knowledge in different contexts and learning environments. In STEM education these digital environments are included in the field of Technology and play an important role in the promotion of children's development (Lindeman, Jabot, Berkley, 2013).

\subsection{Mathematics}

The findings on the Mathematics section hint that teachers integrate this STEM field in their classroom on a satisfactory level. The instruction of mathematics is indeed extremely significant for preschoolers, as it provides valuable knowledge and skills for their future life, such as computational skills. Despite of the teachers' positive view on pre-school mathematics, it is broadly admitted that teachers misunderstand the process of teaching math.

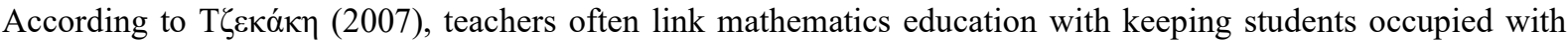
math activities and simply using the names of mathematical concepts in their verbal interactions. Although, this type of math education is inadequate, since it does not help children develop mathematical thinking. The letter "M" in STEM is mostly used to define the instruction of mathematical units, as found in the preschool curriculum of Cyprus. Amongst those units, teachers highlight the usefulness of geometry and numeracy and operations.

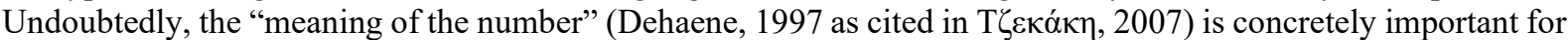
children, as it is the foundation for mathematical reasoning and comprehending complex numerical models

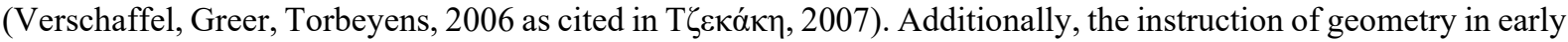

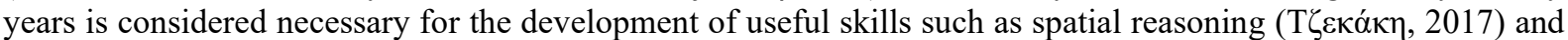

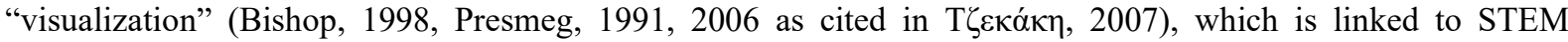
education through the field of Technology. Teachers believe that units of measurement and algebra are less useful

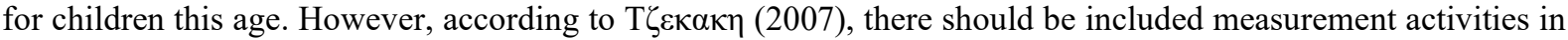
pre-school mathematics, since they provide children the ability to compare objects and understand the use of metric systems. Regarding the instruction of algebra teachers consider that it is less useful, although it is necessary for the children to get acquainted with repeating patterns given that they are capable of developing complex patterning concepts and this expands their cognitive skills (Papic \& Mulligan, 2007).

\subsection{Science}

It is observed that teachers integrate the subject area of science less than math and technology in the activities led in the classroom. Be that as it may, according to teachers' perspectives the instruction of science in preschool classrooms is considered essential and useful. In the past few years, the instruction of science is being included in modern curricula, since it can open up opportunities and help children chase STEM related careers in the future (Mc.Clure et al.,2017). Preschool science is undoubtedly beneficial for children's development; however, it is not always simple to explain and analyze scientific phenomena to preschoolers, because of their cognitive level and limited experiences (P $\alpha \beta \alpha ́ v \eta \varsigma, 2005)$. Teachers also agree on children making hypothesis, taking active part in experiments and sharing their findings. According to Queensland's [The State of Queensland (Queensland

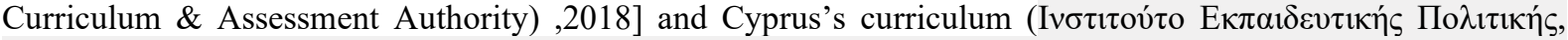

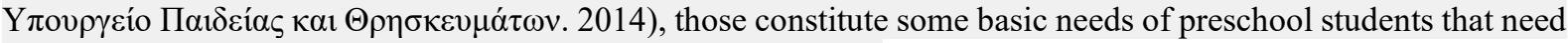
to be covered with science related activities led by the teachers. Apart from these needs, it is useful for children to explore their world around them, so they can observe and understand objects, phenomena and life since they are extremely capable to go through this process (NSTA, 2014 as cited in Mc.Clure, 2017).

\subsection{Engineering}

The field of Engineering is considered the least important of all STEM subject areas, whereas it is the one that combines all STEM disciplines. Like every other section, the majority of the respondents agree with the integration of innovation through engineering. Although, the statistics regarding the perceptions on engineering show a decrease and are not as high as those recorded on the rest STEM fields. On the contrary, research has highlighted the importance of engineering and the important skills acquired through it. Preschool students run into everyday situations that are related with the field of engineering including problem solving and construction processes (Lippard et al., 2018). Children have an innate desire to explore the way the world is structured and functions (Lindeman, Jabot \& Berkley, 2013) so it is important to take advantage of this and relate it with those everyday situations to teach engineering. In the instruction of engineering, students must become acquainted with failure and mistakes and use their experiences to overcome future problems (Rogers, 2012). Not only that, children can use math and science to predict failures and develop their problem-solving skills (Rogers, 2012). Whilst a low level of agreement is observed with respect to the perspectives on the integration of engineering, teachers appear to support the acquisition of engineering skills. These skills are developed through pre-engineering thinking and the "engineering habits of mind" (Lippard et al, 2018). In any case, children are interested in activities that require 
engineering thinking (Bagiati \& Evangelou, 2011 Gold et al., 2015 as cited in Lippard et al., 2018) and are capable in achieving goals in such environments.

\section{Discussion}

The results of this research provide enough evidence to give clear answers to the research questions that were posed earlier on. With respect to the instruction of STEM fields in the Greek preschool classroom, it is reasonable to state that teachers approach these subject areas differently. For instance, math is considered the most important STEM field, when technology and science are less integrated in preschool activities and the instruction of engineering is only mentioned theoretically. The letter "E" in STEM appears to attract the least attention, as teachers believe its integration in modern education curricula is not as important as the rest subject areas. Despite the teachers being not so familiar with STEM related fields, they recognize its importance on preschool education. However, it is insufficient to support such statements only in theory. Apparently, it is more likely that teachers present an ideal situation through their responses, as there is little data that proves the actual use of technology and STEM's instructional practices. Lastly, if we want to make the most of STEM education, we need to accept that the subject areas are interconnected and create a chain. Therefore, the fluctuation between the perspectives on STEM fields and the separate instruction of each subject area is breaking the chain. Nevertheless, teachers' positive perspectives on the importance of STEM can be the first step in integrating the element of innovation in preschool education. It is also extremely important for teachers to be properly trained for STEM, so they can implement their educational methods and make a change in the educational system.

\section{Study Limitations}

Despite the random selection of the sample, there is a great difference between the percentage of women and men teachers that responded. Only 2 men took part in the research and answered the questionnaire, while the rest of the sample consisted of women. Given this large difference, it is harder to draw overall conclusions, as there is not a clear picture of mens' perspectives. Another limitation of the method involves the issue of not defining the type of school in which teachers serve. With this data we could separate the picture for private and state schools, regarding STEM education. Needless to say, our results cast a new light on the pedagogical practices used in Greek kindergarten in general and the perspectives of the teachers on the importance of STEM. The purpose of this study was to investigate how important it is for teachers to upgrade their teaching practices and most certainly how important is STEM for preschoolers. The last limitation of the study is the fact that teachers were not asked about their STEM knowledge, but on the contrary were given the opportunity to meet STEM fields through the questionnaire. Therefore, we cannot examine their knowledge concerning STEM education or whether they are properly trained to apply it in their classroom.

\section{Future Directions}

The conclusions of this research raise new questions that need to be fruitfully explored and answered by future research. Knowing that teachers' perspectives can affect instructional choices, it is reasonable to state that according to the findings of this study, there are teachers that implement STEM practices or teach some of its fields separately. Future research could examine the pedagogical methods that teachers use in their classroom to teach STEM fields. It is therefore useful to investigate teachers' perceptions on the actual implementation of STEM. For example, in the field of engineering it is worth finding out what do teacher think about the use of robotics in preschool education classrooms. Thereby, we will get an actual picture of what teachers are capable of doing in terms of STEM education and their attitude towards the instructional methods used in it. Further studies should also investigate teachers' knowledge concerning STEM education and the training they were provided to integrate modern educational methods in their classrooms.

\section{References}

Aguilar, N. A. (2016). Examining the integration of science, technology, engineering, and mathematics (STEM) in preschool and transitional kindergarten (TK) classrooms using a social-constructivist approach (Doctoral dissertation, Mills College).

Aldemir, J., \& Kermani, H. (2017). Integrated STEM curriculum: improving educational outcomes for head start children. Early Child Development and Care, 187(11), 1694-1706.

Breiner, J. M., Harkness, S. S., Johnson, C. C., \& Koehler, C. M. (2012). What is STEM? A discussion about conceptions of STEM in education and partnerships. School Science and Mathematics, 112(1), 3-11.

Brown, R., Brown, J., Reardon, K., \& Merrill, C. (2011). Understanding STEM: current perceptions. Technology and Engineering Teacher, 70(6), 5.

Bybee, R. W. (2010). Advancing STEM education: A 2020 vision. Technology and engineering teacher, 70(1), 30.

Drigas, A. S., \& Kokkalia, G. K. (2014). ICTs in kindergarten. International Journal of Emerging Technologies 
in Learning, 9(2).

Heylighen, F. (2007). 13 Accelerating socio-technological evolution. Globalization as evolutionary process: modeling global change, 284.

Hwang, J., \& Taylor, J. C. (2016). Stemming on STEM: A STEM education framework for students with disabilities. Journal of Science Education for Students with Disabilities, 19(1), 39-49.

Katsikas, S. K., \& Gritzalis, S. (2017). Digitalization in Greece: State of Play, Barriers, Challenges, Solutions. In Beyond Bureaucracy (pp. 355-375). Springer, Cham.

Lindeman, K. W., Jabot, M., \& Berkley, M. T. (2013). The role of STEM (or STEAM) in the early childhood setting. Chap, 5, 95-113.

Lippard, C. N., Lamm, M. H., Tank, K. M., \& Choi, J. Y. (2019). Pre-engineering thinking and the engineering habits of mind in preschool classroom. Early Childhood Education Journal, 47(2), 187-198.

McClure, E. R., Guernsey, L., Clements, D. H., Bales, S. N., Nichols, J., Kendall-Taylor, N., \& Levine, M. H. (2017). STEM Starts Early: Grounding Science, Technology, Engineering, and Math Education in Early Childhood. In Joan Ganz Cooney Center at Sesame Workshop. Joan Ganz Cooney Center at Sesame Workshop. 1900 Broadway, New York, NY 10023.

McDonald, C. V. (2016). STEM Education: A review of the contribution of the disciplines of science, technology, engineering and mathematics. Science Education International, 27(4), 530-569.

Papic, M., \& Mulligan, J. (2007). The growth of early mathematical patterning: An intervention study.

Rogers, C. (2012). Engineering in kindergarten: How schools are changing. Journal of STEM Education: Innovations and Research, 13(4), 4.

The State of Queensland (Queensland Curriculum \& Assessment Authority) (2018). "Queensland kindergarten learning guideline July 2018", Australia. Retrieved April 20, 2020, from: https://www.qcaa.qld.edu.au/downloads/p_10/qklg_2019.pdf

Wang, M. T., \& Degol, J. L. (2017). Gender gap in science, technology, engineering, and mathematics (STEM): Current knowledge, implications for practice, policy, and future directions. Educational psychology review, 29(1), 119-140.

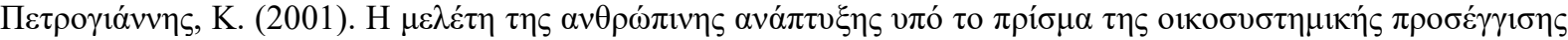

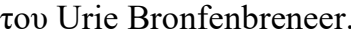

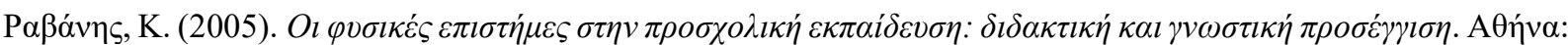
$\Delta \alpha \rho \delta \alpha v o ́ s$.

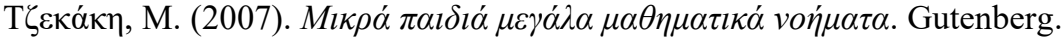

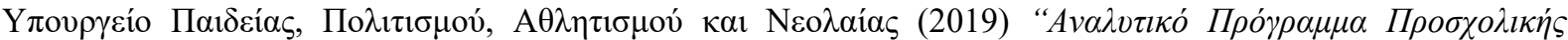

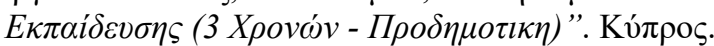

